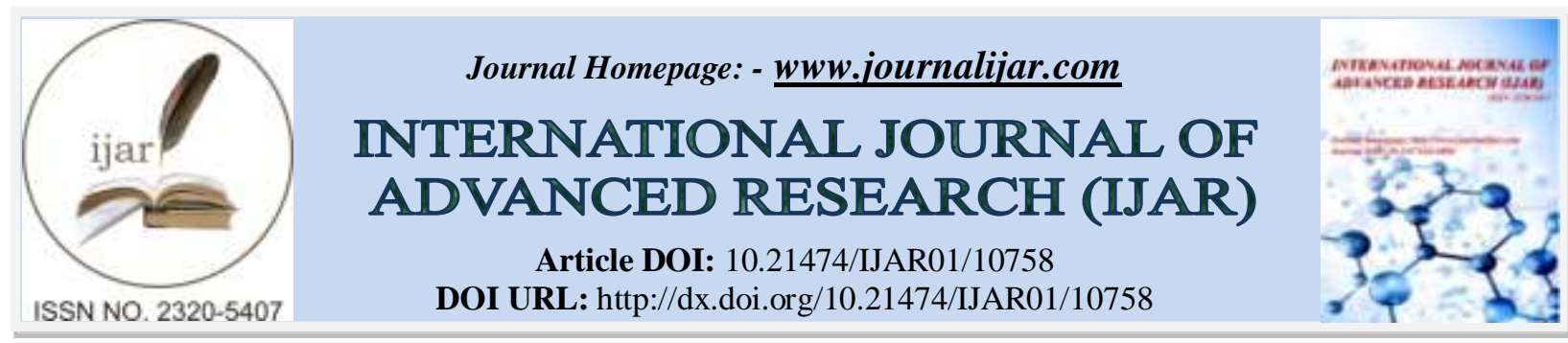

RESEARCH ARTICLE

\title{
LANGUAGE ASSOCIATED PROBLEMS IN TRIBAL RESIDENTIAL SCHOOLS OF KERALA
}

\author{
Muneer. $\mathrm{V}^{\mathbf{1}}$ and Dr. T. Mohamed Saleem ${ }^{2}$ \\ 1. Senior Research Fellow Farook Training College. \\ 2. AssociateProfessor \& Research Guide Farook Training College.
}

\section{Manuscript Info}

Received: 05 February 2020

Final Accepted: 07 March 2020

Published: April 2020

Key words:-

Language Associated Problems, Tribal Residential Schools, Tribal Language, Residential School Teachers, Residential School Students

\section{Manuscript History}

\begin{abstract}
The tribal who constitute $8.8 \%$ of the total population of India, are distributed various states of the country. The tribal culture is entirely different from the way of life of civilized people. Illiteracy is a major problem of the tribals. The medium of instruction is one of the hindrances to the promotion of education among the tribe. Most of the tribal languages do not have a script of their own. Hence the children are obliged to learn things in a language which is foreign to them. Even in tribal areas the number of tribal teachers is very less and hence communication problem always arises between the students and the teachers. Language associated problems are more common in primary classes. In this study investigators conduct a study to find language related problems faced by the tribal residential school teachers and students. For the study 97 tribal residential school teachers 415 residential school students are taken as sample and prepared questionnaire for data collection. Results of the study reveal the different language associated problems and challenges faced by the tribal residential school teachers and students.
\end{abstract}

Copy Right, IJAR, 2020,. All rights reserved.

\section{Introduction:-}

According to Gray language may be regarded as, "any means of expressing emotional and mental concepts by any living being or beings whatsoever and communicating them to or receiving them from other living beings." since language is an expressive medium, it has a universal character. Language is not only a medium of tranaction of education, it is also a mean of growth. At the highest level, language provides a medium of independent and fresh thought and research. In education it must communicate knowledge; it is a tool for gathering information in public life. We need language to gain, preserve and remember our knowledge. This is the child's primary need. Encyclopedia Britannica defines language as "a system of conventional, spoken or written symbols by means of which human beings, as members of a social group and participants in its culture, communicate".

Education is an instrument for transferring the knowledge, culture, and experience of a particular society. It is also helps for socio economic development of the society. Scheduled tribes are the socially underprivileged. Ensuring quality education is an important means of social upliftment of these communities. But nowadays there are many problems with regard to the education of this group. Poverty, lack of awareness, unfavorable social background, linguistic problems etc are the major constraints related to tribal education. Among these, language related problem is important and it also leads to many other problems. Each tribal group has its own unique language and they use such languages at home and among themselves. When children from such background come into mainstream 
education, the language they use there becomes a problem for them. Language related problems may lead to dropout and poor academic performance of students (Sujatha, 2002).

Many researchers studied about the language related problem among scheduled tribes. Studies identified that the language problem is the important constraints of tribal children which prevents them access to education (Sahu, 2014; Punnaiah, 2018). Rani (2000) found that due to the language difficulties the tribal children are find difficulty to establish healthy relationship with the teacher and thus leading to the dropout from their education in some point or the other. Kujur (2019) in his study mentioned that the language related problems not only the indication of exclusion of tribal languages but develops a indifferent attitude among tribal students towards their own languages and undermines their sense of culture and identity. Jha and Jhingran (2002) have strongly advocated the use of the mother tongue or home language as medium of instruction in early stages of education.

The tribal residential school project is aimed at promoting social upliftment of the scheduled tribes through education. In this study, the researchers attempt to study the linguistic difficulties faced by students and teachers of the tribal residential school. Following are the objectives of the present study.

\section{Objectives of the study:-}

1. To find the language associated problems faced by the tribal residential school teachers.

2. To find the language associated problems faced by the tribal residential school students.

\section{Methodology In Brief:-}

Survey method was used to conduct study

\section{Sample:}

97 teachers and 415 students from 17 tribal residential schools of Kerala were participated in the study. Among 97 teachers, 56 are from MRS, 26 are from Ashram schools and 15 are from EMRS. Among 415 students, 205, 138, 72 are from MRS, Ashram school and EMRS respectively.

\section{Tool used:}

Questionnaire on language problems for Teachers and Students are used to collect data. The questionnaire was prepared and validated by researcher.

\section{Statistical techniques used:}

Percentage analysis was used to analyse the collected data.

\section{Results And Discussion:-}

Data collected from tribal residential school teachers and students were analysed using statistical techniques. Data analysis and results are presented under relevant headings.

\section{Language associated problems faced by the tribal residential school teachers:}

Teachers were asked to mark who was experiencing language related problems in tribal residential schools. The number of teachers facing language related problems in tribal residential school class room is presented in table 1

Table 1:- Data and results of number of teachers facing language related problem.

\begin{tabular}{|l|l|l|l|}
\hline \multirow{2}{*}{ Si.No } & \multirow{2}{*}{ Group } & Teachers facing language problems in class room \\
\cline { 3 - 4 } & & N & Percentage \\
\hline 1 & MRS & 7 & 12.5 \\
\hline 2 & Ashram school & 8 & 30.8 \\
\hline 3 & EMRS & 2 & 13.3 \\
\hline 4 & Total & 17 & 17.5 \\
\hline
\end{tabular}

It is clear from the table that $17(17.5 \%)$ tribal residential school teachers faced language related problems in the class room. 7 (12.5\%) of MRS teachers, 8 (30.8\%) of ashram school teachers and 2(13.3\%) of EMRS teachers face language related problems in the classroom. Graphical representation of the result is presented in figure 1 


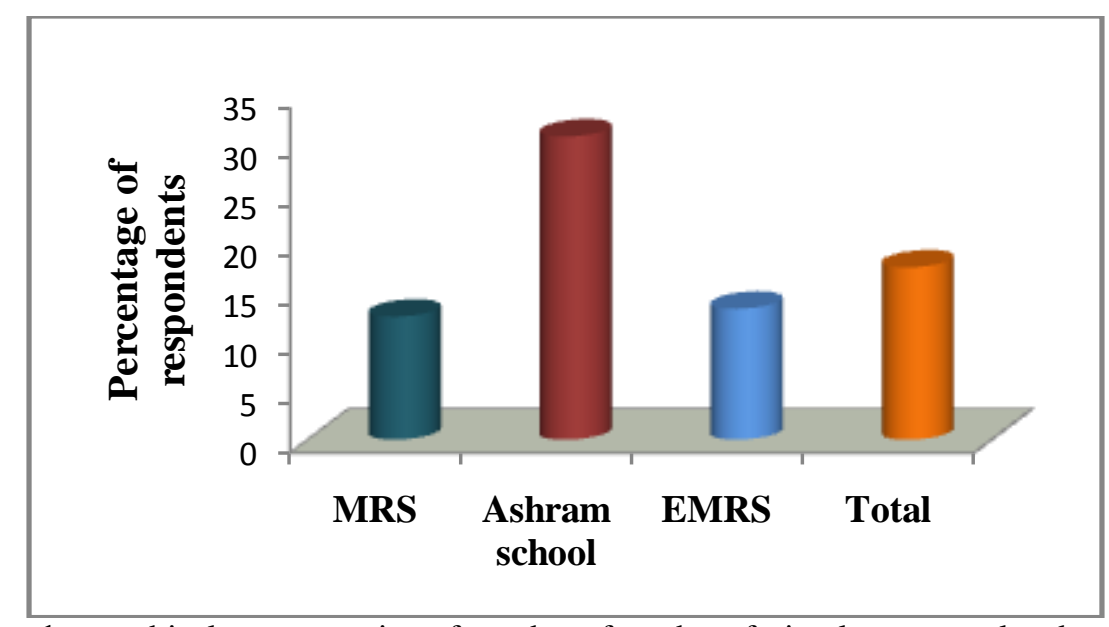

Figure 1:- graphical representation of number of teachers facing language related problem.

Extend of language problem in three grades of classes:

The following table outlines how language related problems are experienced in different grades.

Table 2:- Data and results of extent of language related problem in three grades of classes.

\begin{tabular}{|l|l|l|}
\hline Grade & $\begin{array}{l}\text { Number of teachers faced as small } \\
\text { problem }\end{array}$ & $\begin{array}{l}\text { Number of teachers faced as big } \\
\text { problem }\end{array}$ \\
\hline Lower Primary & 4 & 4 \\
\hline Upper Primary & 9 & 5 \\
\hline High School & 13 & 0 \\
\hline
\end{tabular}

From table 2 it is clear that, 13 high school, 9 upper primary and 4 lower primary teachers faced language related problem as small problem and 5 upper primary and 4 lower primary teachers faced language related problem as big problem..

Areas of teaching process - experiencing language problems:

Teachers were asked to mark which areas were experiencing language related problems. The following table outlines which areas teachers have encountered in the language related problems.

Table 3:- Data and results of areas of teaching process are experiencing language related problems.

\begin{tabular}{|l|l|l|l|}
\hline \multirow{2}{*}{ Grade } & Areas of teaching process & \multicolumn{2}{|l|}{} \\
\cline { 2 - 4 } & $\begin{array}{l}\text { To convey textbook } \\
\text { ideas to students. }\end{array}$ & $\begin{array}{l}\text { For communication with } \\
\text { students }\end{array}$ & $\begin{array}{l}\text { To establish proper relationship } \\
\text { with students }\end{array}$ \\
\hline Lower Primary & 7 & 4 & 4 \\
\hline Upper Primary & 11 & 5 & 3 \\
\hline High School & 12 & 3 & 4 \\
\hline
\end{tabular}

Table 3 showed that 12 high school, 11 upper primary and 7 lower primary teachers faced language as barrier to convey textbook ideas to students. 3 high school, 5 upper primary and 4 lower primary teachers have encountered language as a problem to communicate properly with students. Language has become a barrier for 4 high school, 3 upper primary and 4 lower primary teachers to establish proper relationship with students.

Language related problem faced by the tribal residential school students:

The tribal residential school students were asked if they had ever experienced language difficulties in residential school life. Their responses in this regards based on type of school is presented in Table 4.

Table 4:- Data and results of language difficulties in residential school life.

\begin{tabular}{|l|l|l|l|}
\hline Si.No & Type of school & \multicolumn{2}{|l|}{ Number of students faced language problems in class room } \\
\cline { 3 - 4 } & & $\mathrm{N}$ & Percentage \\
\hline
\end{tabular}




\begin{tabular}{|l|l|l|l|}
\hline 1 & MRS & 18 & 8.8 \\
\hline 2 & Ashram school & 52 & 37.7 \\
\hline 3 & EMRS & 11 & 15.3 \\
\hline 4 & Total & 81 & 19.5 \\
\hline
\end{tabular}

(N, MRS- 205, Ashram-138, EMRS -72, Total - 415)

From table 4 it is clear that the number of model residential school students faced language related problem is 18 ( $8.8 \%)$, number of ashram school students faced language related problem is $52(37.7 \%)$ and the number of eklavya model residential school students faced language related problem is $11(15.3 \%)$.a total of $81(19.5 \%)$ tribal residential school students faced language related problems in residential school life. The graphical representation of the result is presented in figure 2

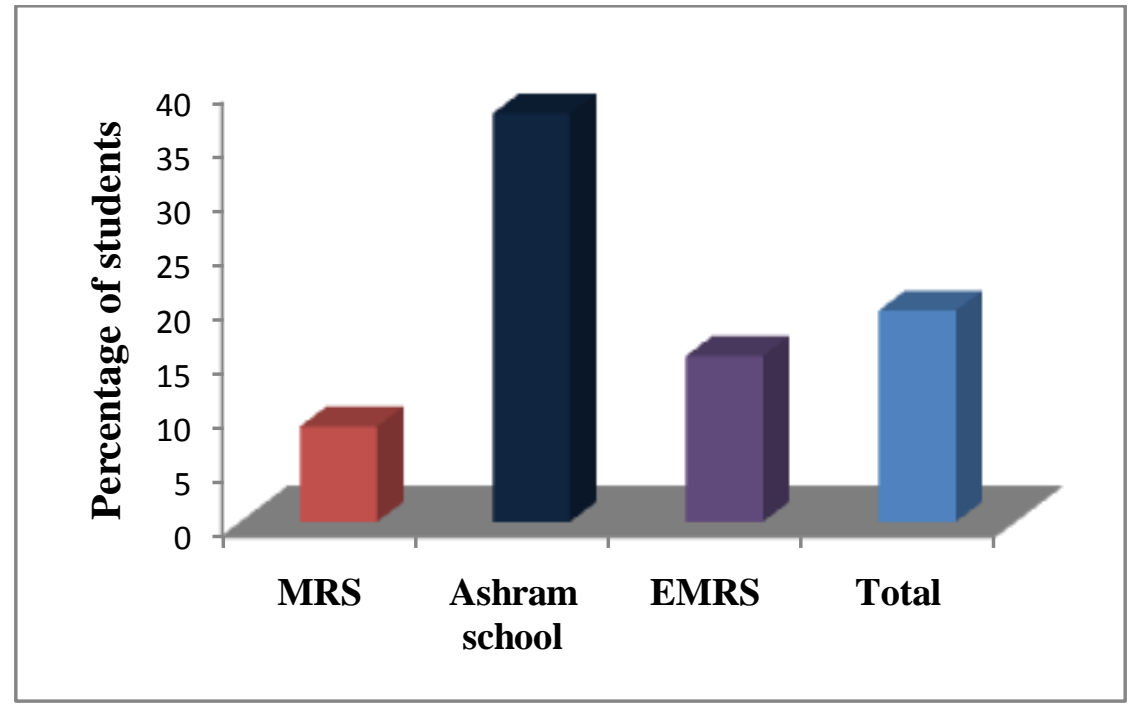

Figure 2:- Graphical representation of language related difficulties in residential school life.

The tribal residential school students were asked in which grade they experienced language difficulties in residential school life. Their responses in this regards based on grade is presented in Table.5

Table 5:- Data and results of language difficulties in residential school life- grade wise.

\begin{tabular}{|l|l|l|l|}
\hline Si.No & Grade & N & \% \\
\hline 1 & Lower Primary & 46 & 56.8 \\
\hline 2 & Upper Primary & 50 & 61.7 \\
\hline 3 & High School & 12 & 14.8 \\
\hline
\end{tabular}

Table 5 revealed that, the number of students faced language related problems at lower primary level is 46 (56.8\%), the number of students faced language related problems at upper primary level is $50(61.7 \%)$ and the number of students faced language related problems at high school level is $12(14.8 \%)$.

The following section summarizes the various situations that students with language related problems encountered. List of the various contexts in which language related problems are encountered and percentages of students experiencing that particular situations are presented in table 6

Table 6:- Data and result of various situations that students with language related problems encountered.

\begin{tabular}{|l|l|l|l|}
\hline Si.No. & Situation & $\mathbf{N}$ & \% \\
\hline $\mathbf{1}$ & To understand the class & 30 & 37.03 \\
\hline $\mathbf{2}$ & To talk to teachers & 49 & 60.49 \\
\hline $\mathbf{3}$ & To talk to friends & 15 & 18.51 \\
\hline $\mathbf{4}$ & To read the text book & 37 & 45.68 \\
\hline $\mathbf{5}$ & To participate in group activities & 19 & 23.46 \\
\hline
\end{tabular}




\begin{tabular}{|l|l|l|l|}
\hline $\mathbf{6}$ & To express your own opinions boldly & 25 & 30.86 \\
\hline $\mathbf{7}$ & To take over the leadership of the class and club activities & 18 & 22.22 \\
\hline $\mathbf{8}$ & To participate in arts programmes. & 22 & 27.16 \\
\hline $\mathbf{9}$ & To speak to outsiders without fear & 31 & 38.27 \\
\hline
\end{tabular}

From table 6 it is clear that, $60.49 \% \mathrm{f}$ of respondents said that language has become a problem for talk with teachers. $45.68 \%$ of students responded that language has become a problem for them to read textbooks. $38.27 \%$ commented that the language created a problem for speaking without fear of outsiders. $37.03 \%$ of responded students faces difficult to understand the class. About $30.86 \%$ of students responded that because of language problem they were not able to express their views boldly. $27.16 \%$ of students responded that they face to difficulty to participate in arts programmes. $23.46 \%$ of students to responded that they face difficult to participate in group activities. $22.22 \%$ of students responded that they face difficulty to take over the leadership of the class and club activities. Least percentage of students $(18.51 \%)$ responded that they facing difficulty to speak with friends.

\section{Conclusion:-}

Many studies have found that language related problems can negatively impact the education of ST students. It is clear from the results of the present study that less than $20 \%$ of the teachers and students of the tribal residential school have faced language related problem. For most teachers, the language related problem is perceived as a minor problem. Most of the teachers faced language as barrier to convey textbook ideas to students. These kinds of problems for teachers can negatively impact the academic performance of ST students. It is clear from the study that language is became a problem for students to understand the class. Most students are experiencing language problems at upper primary and lower primary level. therefore, there is a need for the appointment of teachers/mentors who are capable of handle the tribal language to ST students in lower grades. These teachers can act as a link for students to reach instructional language from local language. Such initiatives, to some extent, can help alleviate the language problems of scheduled tribe students

\section{References:-}

1. Jha, J., \& Jhingran, D. (2002). Elementary Education for the Poorest and Other Deprived Groups, Centre for Policy Research. New Delhi.

2. Kujur, A.S. (2019). Educational Exclusion: Adivasis' Experiences of formal Schooling in India. International Journal of Innovative Studies in Sociology and Humanities, 4(1), 55-63.

3. Punnaiah, D. A. (2018). Issues and challenges of tribal education: A study of Telangana state. International Education \& Research Journal, 4(1), 49-51.

4. Rani, M. (2000). Tribal Languages and Tribal Education. Social Action, 50 , 414-418.

5. Sahu, K. K. (2014). Challenging issues of tribal education in India. IOSR Journal of Economics and Finance, $3(2), 48-52$.

6. Sujatha, K. (2002). Education among scheduled tribes. India Education Report: A Profile of Basic Education, New Delhi: OUP. 